\title{
Undiagnosed COPD in Patients with Established Cardiovascular Diseases: Prevalence, Symptoms Profiling and Functional Status
}

\section{Li-Cher Loh ${ }^{1 *}$, Narentharen Selvarajah', Shanthiny Mohan', Wai-Sun Choo ${ }^{1}$ and Ismail Omar ${ }^{2}$}

${ }^{1}$ Department of Medicine, Penang Medical College, Penang, Malaysia

${ }^{2}$ Department of Cardiology, Penang Hospital, Penang, Malaysia

\section{Abstract}

Background: COPD is associated with cardiovascular co-morbidities. We examined the prevalence of undiagnosed COPD in our local population of patients with stable cardiovascular diseases and the profile of their respiratory symptoms and functional status.

Methods: Eligible patients with established stable cardiovascular diseases were prospectively recruited from the cardiology outpatient clinic of an urban-based university teaching hospital and evaluated with pre- and postbronchodilator spirometry testing and interview using standard questionnaire.

Results: Of the 501 subjects recruited, $113(22.6 \%)$ had COPD defined on post-bronchodilator fixed $\mathrm{FEV}_{1} / \mathrm{FVC}$ ratio $<70 \% .109(96.5 \%)$ had moderate severity while only $4(3.5 \%)$ had severe disease by GOLD classification. Compared to non-COPD, proportionately more COPD patients were older, males, exposed to cigarette smoking (including passive smoking) and had congestive cardiac failure and pulmonary hypertension. Also proportionately more COPD subjects had more cough, sputum and dyspnoae, and poorer scores in MRC dyspnoae scale, NYHA functional class and SGRQ quality of life. These symptoms were generally worst in the evening. They also had significantly higher mean number of unscheduled visits to outpatient clinics, emergency departments and of hospital admissions over the past 12 months. After multivariate analysis, only dyspnoae [odd ratio $(95 \% \mathrm{Cl}): 4.2(1.8-9.7) ; \mathrm{p}=0.001$ ] and cigarette smoking [2.8 (1.1-6.80); 0.018] remained independently associated with COPD.

Conclusions: A significant proportion of patients with established cardiovascular diseases have undiagnosed COPD of moderate severity. Dyspnoae and cigarette smoking appear highly predictive of COPD.

Keywords: COPD; Cardiovascular Diseases; Malaysia; Prevalence; Symptoms

\section{Introduction}

Chronic obstructive pulmonary disease (COPD) is associated with increased cardiovascular comorbidities that are not fully explained by cigarette smoking alone [1]. The prevalence, most of which are ishaemic heart disease and cardiac failure, is probably between 10 and $40 \%$ among COPD patients from different studied cohorts [2-4]. However, prevalence of COPD among patients with established cardiovascular diseases is less well documented. It is probably between 8 and $12 \%$ in ishaemic heart disease $[5,6]$ and may be as high as $40 \%$ in cardiac failure [7]. The frequent coexistence of these two conditions requires that we understand better their mutual prevalence in order not to miss out on the treatment of either one of them.

COPD is generally under-diagnosed for a variety of reasons. In patients with cardiovascular diseases, symptoms like breathlessness and cough can be indicative of both respiratory and cardiac conditions [8], making COPD more unsuspecting. Currently, international society is pushing for greater awareness of COPD and its early diagnosis with emphasis on spirometry. Such advocacy to reliably diagnose COPD is even more crucial in patients with established cardiovascular diseases as the respiratory symptoms may be masked by the cardiac complaint.

The prevalence of COPD in Malaysia is estimated at $4.7 \%$ which is positioned at intermediate range among the Asia-Pacific countries of highly heterogeneous people [9]. Similar to other countries worldwide, many of our patients at diagnosis of COPD have already established disease with poor quality of life and frequent hospital admissions [10]. The importance and urgency in diagnosing and treating COPD early is now more obvious than ever in at risk population including those with cardiovascular diseases. For these purposes, we sought to study the prevalence of undiagnosed COPD among a local population of Malaysian patients with stable cardiovascular diseases by examining for the presence of airflow obstruction by means of spirometry and also to examine for associations with clinic-demographic characteristics that might help to predict COPD from non-COPD in these patients.

\section{Subjects and Methods}

Subjects: From 1 November to 31 December 2009, all patients followed up in cardiology clinic of an urban-based 1200-bed teaching hospital were consecutively screened for eligibility. Included were patients with age $\geq 40$ yrs with cardiovascular diseases that had been stable (i.e. no adjustment of treatment or requiring particular intervention including hospital admission) for at least one month. These conditions accepted for study were hypertension, hyperlipidaemia, ischemic heart disease (confirmed with coronary angiography), congestive cardiac failure (with echocardiographic evidence), arrhythmias, valvular heart disease, and pulmonary hypertension (either primary or secondary). Excluded were patients previously diagnosed with COPD, asthma, pulmonary fibrosis or other chronic lung diseases, who had used bronchodilator therapy in the prior one month, or who were unable to perform spirometry

*Corresponding author: Dr. Li-Cher Loh, Professor of Medicine \& Head, Department of Medicine, Penang Medical College, 4 Jalan Sepoy Lines, Penang 10450 Malaysia, Tel: 604226 3459; Fax: 604227 6529; E-mail: richard_loh@pmc. edu.my

Received August 08, 2011; Accepted November 06, 2011; Published November 08, 2011

Citation: Loh LC, Selvarajah N, Mohan S, Choo WS, Omar I (2011) Undiagnosed COPD in Patients with Established Cardiovascular Diseases: Prevalence, Symptoms Profiling and Functional Status. J Pulmonar Respirat Med 1:107. doi:10.4172/2161-105X.1000107

Copyright: @ 2011 Loh LC, et al. This is an open-access article distributed under the terms of the Creative Commons Attribution License, which permits unrestricted use, distribution, and reproduction in any medium, provided the original author and source are credited. 
for whatever reasons. The protocol of this prospective observational study was approved by the Ethics and Medical Research Committee, Ministry of Health Malaysia, and registered under National Medical Research Registrar (NMRR-09-400-4111). Written informed consent was obtained from all recruited patients.

Study design: In a single visit, recruited patients provided all relevant data via personal interview (by NS and MS) and from their medical records. They then carried out pre- and post-bronchodilator spirometry testing. Data collected using a standard questionnaire form developed for the study consisted of socio-demographic and occupational details, cigarette exposure, types of cardiovascular diseases, severity, frequency and timing of respiratory symptoms, Medical Research Council (MRC) Dyspnoae Scale [11], New York Heart Association (NYHA) functional class [12], St George's Respiratory Questionnaire (SGRQ) scores [13], and pre- and post-bronchodilator spirometry results. SGRQ data was only collected if patients have the described respiratory symptoms.

Respiratory symptoms: Four symptoms of cough, sputum, noisy breathing (or wheeze) and breathlessness were profiled from the perspective of frequency and "being troubled", graded on a 5-point Liskert score of "never", "rarely", "sometimes", "often" and "always". Similar to another COPD study of European patients [14], our patients were also asked on the timing of the day when these symptoms were worst, or whether such pattern was readily discernable.

Spirometry testing: Spirometry was performed according to ATS/ ERS guidelines [15] using Micro Plus ${ }^{\mathrm{TM}}$ spirometry (Cat. No. MS03, MicroMedical Ltd, UK), performance of which had been previously validated [16]. FEV and FVC were measured at baseline and 15 to 30 minutes after two puffs of salbutamol (Ventolin ${ }^{\text {mix }}$ Evohaler $^{\text {rx }} 100$ micrograms). Lung Function Calculator LN-37 provided normative range for $\mathrm{FEV}_{1}$ and FVC from European Respiratory Society [17]. Caucasian normative reference was used for the purpose of this study.

Airflow obstruction and COPD: Airflow obstruction is defined as post-bronchodilator $\mathrm{FEV}_{1} / \mathrm{FVC}$ ratio of $<0.7$ and considered to have undiagnosed COPD for the purpose of our study. The use of fixed $\mathrm{FEV}_{1} / \mathrm{FVC}$ ratio, instead of Lower Limits of Normal (LLN) as criteria for airflow obstruction is intentional as we do not have the appropriate normative range of $\mathrm{FEV}_{1}$ and $\mathrm{FVC}$ for our multiethnic patient population at the time of the study.

Statistical analysis: Categorical and continuous data were presented using standard descriptive statistics. Analysis is performed to look at possible differences of characteristics between COPD and non-COPD subjects with either chi square or student $t$ tests depending on whether they are categorical or continuous data. Variables shown to be univariately associated with COPD are further examined by logistic regression analysis for their degree of independence in various predictive models. Adjusted odd ratios with $95 \% \mathrm{CI}$ are also calculated accordingly. $\mathrm{P}<0.05$ is considered significant and is two-tailed.

\section{Results}

5 patients declined the study despite being eligible. Of the 501 subjects successful recruited, $113(22.6 \%)$ had airflow obstruction indicative of COPD for the purpose of this study. Socio-demographic characteristics that were significantly associated with the COPD group, compared with non-COPD, are male and cigarette smoking status (Table 1). The latter consisted of having ever smoked, being current smokers, passive smokers and mean cigarette pack yrs. Over $50 \%$ of the subjects recruited had ischemic heart disease, hypertension and hyperlipidaemia. Compared with non-COPD, COPD group had significantly higher proportions of congestive cardiac failure and pulmonary hypertension (Table 2).
Compared with non-COPD, significantly higher proportions of COPD subjects were troubled much by cough, sputum and dyspnoea, and had more frequent sputum and dyspnoea. However, there is no significantly difference in the complaint of noisy breathing between the two groups. Compared with non-COPD, significantly higher proportions of COPD also had poorer scores in MRC dyspnoea scale and NYHA functional class. In quality of life measures, COPD subjects, compared with non-COPD, had lower mean SGRQ scores in symptoms, activity, impact and in totality. From the perspective of healthcare utilization, COPD subjects compared to non-COPD, had significantly higher mean number of unscheduled visits in the past 12 months to outpatient clinics, accident \& emergency departments and higher mean number of hospital admissions. All these data are shown in (Table 3).

On the times of the day where complaints are worst, proportionately more COPD subjects had their cough and sputum worst in the evenings compared to non-COPD subjects. However, there appeared to be no significant difference in dyspnoea between the two groups according to the times of the day (Figure 1).

\begin{tabular}{|c|c|c|c|c|}
\hline & $\begin{array}{l}\text { Entire } \\
\text { group } \\
(n=501)\end{array}$ & $\begin{array}{l}\text { COPD } \\
(n=133)\end{array}$ & $\begin{array}{l}\text { Non-COPD } \\
(n=388)\end{array}$ & $\mathrm{P}^{*}$ \\
\hline Age, mean yr (SD) & $61(10.6)$ & $63(10.3)$ & $61(10.7)$ & 0.037 \\
\hline Male & 345 (68.9) & $98(86.7)$ & $247(63.7)$ & $<0.001$ \\
\hline \multicolumn{5}{|l|}{ Ethnicity } \\
\hline Malay & $161(32.1)$ & $34(30.1)$ & $127(32.7)$ & - \\
\hline Chinese & $240(47.9)$ & $56(49.6)$ & $184(47.4)$ & - \\
\hline Indian & $93(18.6)$ & $23(20.4)$ & $70(18.0)$ & 0.464 \\
\hline \multicolumn{5}{|l|}{ Education level } \\
\hline No primary & $80(16.0)$ & $16(14.2)$ & $64(16.5)$ & - \\
\hline Primary only & $80(16.0)$ & $23(20.4)$ & $57(14.7)$ & - \\
\hline Secondary only & $258(51.5)$ & $60(53.1)$ & $198(51.0)$ & - \\
\hline Diploma or university & $80(16.0)$ & $14(12.4)$ & $66(17.0)$ & - \\
\hline Postgraduate & $2(0.4)$ & $0(0)$ & $2(0.5)$ & 0.525 \\
\hline \multicolumn{5}{|l|}{ Occupation } \\
\hline Professional & $43(8.6)$ & $9(8.0)$ & $34(8.8)$ & - \\
\hline Non-professional & 458 (91.4) & $104(92.0)$ & $354(91.2)$ & 0.790 \\
\hline \multicolumn{5}{|l|}{ Total family income per month** } \\
\hline$<R M 1000$ & $344(68.7)$ & $84(74.3)$ & $260(67.0)$ & - \\
\hline$R M 1000-3000$ & $148(29.5)$ & $29(25.7)$ & $119(30.7)$ & - \\
\hline RM3001-5000 & $7(1.4)$ & $0(0)$ & $7(1.8)$ & - \\
\hline$>R M 5000$ & $2(0.4)$ & $0(0)$ & $2(0.5)$ & 0.256 \\
\hline Body Mass Index, mean (SD) & $26(4.0)$ & $27(16.1)$ & $26(4.4)$ & 0.412 \\
\hline Abdominal girth in $\mathrm{cm}$, mean (SD) & $94(11.8)$ & $94(14.8)$ & $94(13.0)$ & 0.892 \\
\hline \multicolumn{5}{|l|}{ Cigarette smoking status } \\
\hline Ever & $255(50.9)$ & $94(83.2)$ & $161(41.5)$ & $<0.001$ \\
\hline Current & $71(14.2)$ & $24(21.2)$ & $47(12.1)$ & 0.014 \\
\hline Passive & $158(31.5)$ & $52(46.0)$ & $106(27.3)$ & $<0.001$ \\
\hline Pack yrs, mean (Cl) & $14(12-15)$ & $25(21-28)$ & $10(8-12)$ & $<0.001$ \\
\hline \multicolumn{5}{|l|}{ Occupation exposure } \\
\hline Dust & $118(23.6)$ & $27(23.9)$ & $91(23.5)$ & 0.923 \\
\hline Yrs exposed to dust, mean (SD) & $24(9.9)$ & $29(10.3)$ & $25(9.5)$ & 0.139 \\
\hline Chemical or gas & $43(8.6)$ & $8(7.1)$ & $35(9.0)$ & 0.517 \\
\hline $\begin{array}{l}\text { Yrs exposed to chemical/gas, } \\
\text { mean (SD) }\end{array}$ & $23(10.5)$ & $27(12.3)$ & $23(10.8)$ & 0.419 \\
\hline
\end{tabular}

Values are numbers with percentages in parenthesis, unless otherwise stated $(\mathrm{SD}=$ standard deviation; $\mathrm{Cl}=95 \%$ confidence level).

*p between COPD and non-COPD subjects

${ }^{* *} \mathrm{RM}=$ Malaysian Ringgit (Malaysian currency)

Table 1: Socio-demographic characteristics of subjects. 
Citation: Loh LC, Selvarajah N, Mohan S, Choo WS, Omar I (2011) Undiagnosed COPD in Patients with Established Cardiovascular Diseases: Prevalence, Symptoms Profiling and Functional Status. J Pulmonar Respirat Med 1:107. doi:10.4172/2161-105X.1000107

Page 3 of 5

\begin{tabular}{|l|l|l|l|l|}
\hline & $\begin{array}{l}\text { Entire group } \\
(\mathrm{n}=501)\end{array}$ & $\begin{array}{l}\text { COPD } \\
(\mathrm{n}=133)\end{array}$ & $\begin{array}{l}\text { Non-COPD } \\
(\mathrm{n}=388)\end{array}$ & $\mathrm{P}^{*}$ \\
\hline Hypertension & $350(69.9)$ & $81(71.7)$ & $269(69.3)$ & 0.632 \\
\hline Hyperlipidaemia & $312(62.3)$ & $65(57.5)$ & $247(63.7)$ & 0.236 \\
\hline Ishaemic heart disease & $381(76.0)$ & $87(77.0)$ & $294(75.8)$ & 0.789 \\
\hline Congestive cardiac failure & $25(5.0)$ & $10(8.8)$ & $15(3.9)$ & 0.032 \\
\hline Arrhythmia & $124(24.8)$ & $33(29.2)$ & $91(23.5)$ & 0.213 \\
\hline Valvular heart disease & $85(17.0)$ & $15(13.3)$ & $70(18.0)$ & 0.235 \\
\hline Pulmonary hypertension & $15(3.0)$ & $8(7.1)$ & $7(1.8)$ & 0.004 \\
\hline
\end{tabular}

Values are numbers with percentages in parenthesis

${ }^{*} p$ between COPD and non-COPD subjects

Table 2: Pattern of cardiovascular diseases among subjects.

\begin{tabular}{|c|c|c|c|c|}
\hline & $\begin{array}{l}\text { Entire group } \\
(n=501)\end{array}$ & $\begin{array}{l}\text { COPD } \\
(n=133)\end{array}$ & $\begin{array}{l}\text { Non-COPD } \\
(\mathrm{n}=388)\end{array}$ & $\mathrm{P}^{*}$ \\
\hline \multicolumn{5}{|l|}{ Cough } \\
\hline Trouble less & $470(93.8)$ & 99 (87.6) & 371 (95.6) & - \\
\hline Trouble much & $31(6.2)$ & $14(12.4)$ & $17(4.4)$ & 0.002 \\
\hline \multicolumn{5}{|l|}{ Sputum } \\
\hline Less frequent & $470(93.8)$ & $100(88.5)$ & $370(95.4)$ & - \\
\hline Much frequent & $31(6.2)$ & $13(11.5)$ & $18(4.6)$ & 0.008 \\
\hline Trouble less & $470(93.8)$ & $101(89.4)$ & 369 (95.1) & - \\
\hline Trouble much & $31(6.2)$ & 12 (10.6) & $19(4.9)$ & 0.026 \\
\hline \multicolumn{5}{|l|}{ Noise breathing } \\
\hline Less frequent & $496(99.0)$ & $111(98.2)$ & 385 (99.2) & - \\
\hline Much frequent & $5(1.0)$ & $2(1.8)$ & $3(0.8)$ & 0.348 \\
\hline \multicolumn{5}{|l|}{ Dyspnoea } \\
\hline Less frequent & $429(85.8)$ & 76 (67.9) & $353(91.0)$ & - \\
\hline Much frequent & 71 (14.2) & 36 (32.1) & $35(9.0)$ & $<0.001$ \\
\hline Trouble less & $431(86.2)$ & $77(68.8)$ & $354(91.2)$ & - \\
\hline Trouble much & $69(13.8)$ & 35 (31.3) & $34(8.8)$ & $<0.001$ \\
\hline \multicolumn{5}{|l|}{ MRC** Dyspnoae Scale } \\
\hline Grade 0 & $44(8.8)$ & $7(6.2)$ & $37(9.5)$ & - \\
\hline Grade 1 & $248(49.5)$ & 41 (36.3) & $207(53.4)$ & - \\
\hline Grade 2 & $148(29.5)$ & $34(30.1)$ & $114(29.4)$ & - \\
\hline Grade 3 & 54 (10.8) & $30(26.5)$ & $24(6.2)$ & - \\
\hline Grade 4 & $7(1.4)$ & $1(0.9)$ & $6(1.5)$ & $<0.001$ \\
\hline \multicolumn{5}{|l|}{ NYHA $^{\epsilon}$ Functional Class } \\
\hline Class 1 & $136(27.1)$ & $21(18.6)$ & $115(29.6)$ & - \\
\hline Class 2 & $288(57.5)$ & $55(48.7)$ & $233(60.1)$ & - \\
\hline Class 3 & $70(14.0)$ & $37(32.7)$ & $33(8.5)$ & - \\
\hline Class 4 & $7(1.4)$ & $0(0.0)$ & $7(1.8)$ & $<0.001$ \\
\hline \multicolumn{5}{|c|}{ SGRQ $¥$ mean (SD) scores } \\
\hline Symptoms score & $40(20.0)$ & $46(23.5)$ & $37(16.5)$ & 0.009 \\
\hline Activity score & $50(21.5)$ & $57(21.7)$ & $47(20.7)$ & 0.007 \\
\hline Impact score & $29(24.9)$ & 40 (29.5) & $23(18.5)$ & $<0.001$ \\
\hline Total score & $37(20.9)$ & $46(24.0)$ & $32(16.6)$ & $<0.001$ \\
\hline \multicolumn{5}{|l|}{$\begin{array}{l}\text { Healthcare utilization in } \\
\text { past } 12 \text { months }{ }^{£}\end{array}$} \\
\hline Outpatient visits & $0.29(1.18)$ & $0.82(1.82)$ & $0.13(0.86)$ & $<0.001$ \\
\hline$A \& E$ visits & $0.27(1.13)$ & $0.72(1.68)$ & $0.14(0.87)$ & $<0.001$ \\
\hline Hospital admissions & $0.24(1.02)$ & $0.62(1.41)$ & $0.13(0.85)$ & $<0.001$ \\
\hline
\end{tabular}

Values are numbers with percentages in parenthesis, unless otherwise stated.

*p between COPD and non-COPD subjects

** MRC $=$ Medical Research Council

${ }^{\epsilon} \mathrm{NYHA}=$ New York Heart Association

${ }^{*} \mathrm{SGRQ}=$ St George's Respiratory Questionnaire (data only collected in 56 COPD and 86 non-COPD subjects)

${ }^{\varepsilon}$ expressed in mean (SD) of unscheduled events not confined to cardiac causes alone.

Table 3: Profile of respiratory symptoms, dyspnoae scores, quality-of-life status and healthcare utilisation among COPD and non-COPD subjects.

All variables that are significantly associated with COPD subjects were selected for logistic regression analysis. The exceptions are NYHC functional class, degrees of being troubled by sputum and by dyspnoea because of their close correlations to their counterpart measurements of MRC score, sputum and dyspnoea frequencies. SGRQ data are also not included for regression analysis because of the reduced data set

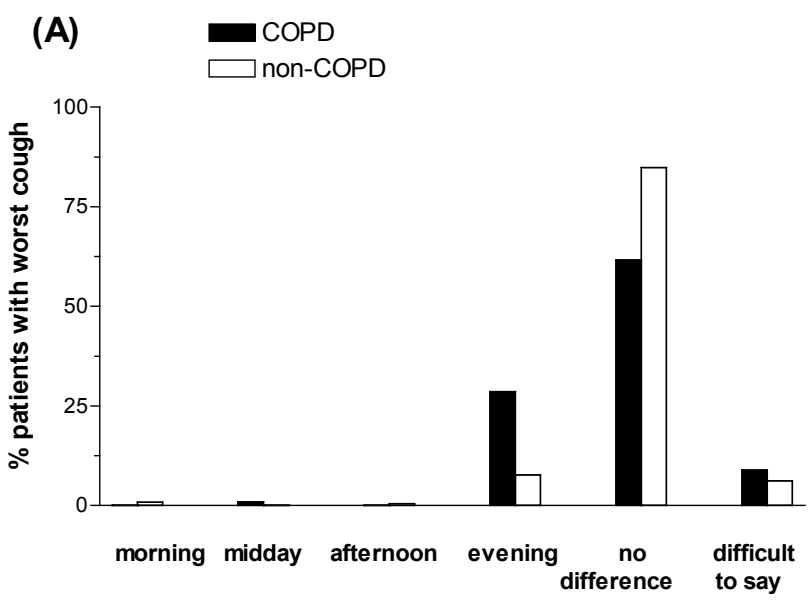

(B) $\quad$ COPD

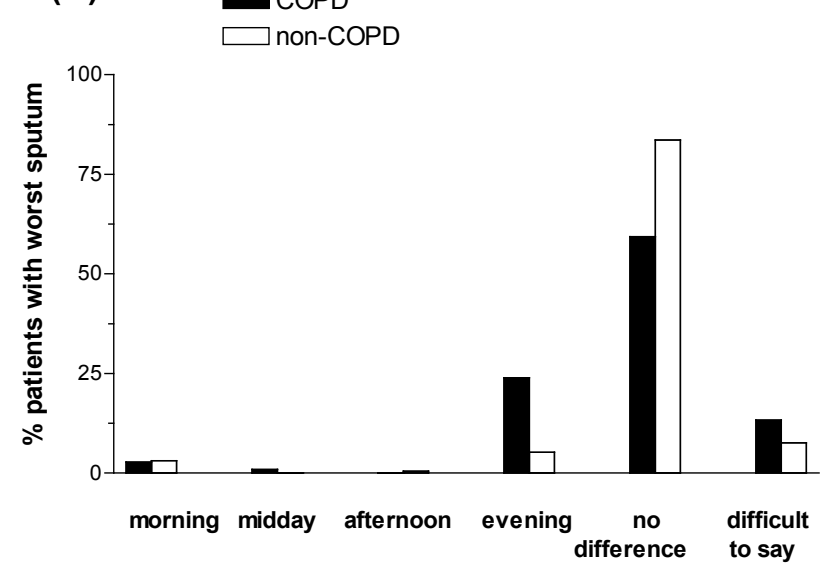

(C)

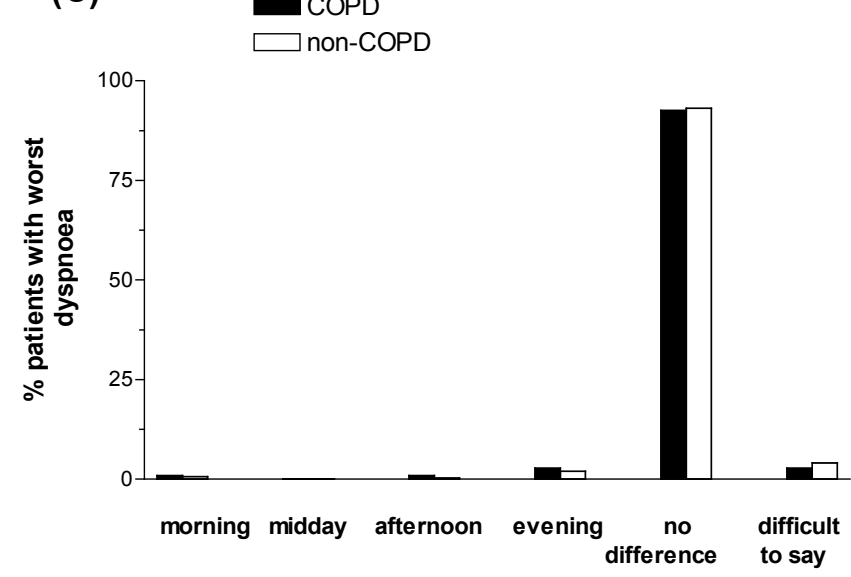

Figure 1: Percentage of patients with worst complaint of symptoms of (A) cough (B) sputum (C) dyspnoea according to the different times of the day. 
since only those with respiratory symptoms were evaluated on SGRQ according to the study protocol. The prediction model generated showed that only cigarette smoking (having ever- smoked) and dyspnoea remained independently associated with COPD (Table 4).

Based on GOLD classifications of COPD severity, 109 (96.5\%) had moderate severity while only 4 (3.5\%) had severe disease. There were no subjects with mild or very severe disease. Bronchodilator reversibility in mean $(\mathrm{CI})$ percentage changes in post-bronchodilator $\mathrm{FEV}_{1}$ for COPD and non-COPD subjects were $-1.4(-2.8$ to 0.05$)$ and 5.2 (4.5 to 5.9$)$ respectively.

\section{Discussion}

In a prospectively collected data, we have shown that a significant proportion of our local patients with stable cardiovascular diseases have $\mathrm{COPD}$ on the basis of airflow obstruction by fixed $\mathrm{FEV}_{1} / \mathrm{FVC}$ ratio. They are more associated with being older and male, with cigarette smoking and having congestive cardiac failure and pulmonary hypertension. They have more cough, sputum and breathlessness, are associated with poorer functional and quality-of-life status and utilized more healthcare resources. Multivariate analysis showed that breathlessness and cigarette smoking are independently associated with COPD by an increased likelihood of two to four times. Also importantly, almost all these COPD patients have moderate severity by GOLD classification. Their symptoms are generally worse in the evenings.

While the majority of the cardiovascular diseases studied here are hypertension, hyperlipidaemia and ischemic heart disease, it is congestive cardiac failure and pulmonary hypertension that are shown to be associated with COPD. The frequency of COPD is found to be 10 out of the 25 patients with cardiac failure, giving rise to a figure of $40 \%$. In a retrospective study of 186 clinic patients by Mascarenhas J et al. [7], the prevalence of COPD among patients with left ventricular systolic dysfunction was found to be $39.2 \%$. Another cross-sectional study from 61 Scottish primary care practices of 377439 patients showed that the prevalence of COPD in their heart failure patients was $23.8 \%$ in 2004 [18]. It is important to realize that acute heart failure can produce an obstructive lung impairment that disappears with treatment [19]. As such, the figures reported may be inaccurately high in any retrospective study where the control of heart failure could not be fully ascertained [8]. Nevertheless, the prospective nature of our data and that only stable patients were recruited reduce the likelihood of such lung function inaccuracies caused by uncontrolled or acute heart failure.

In a newly published study by Wada $\mathrm{H}$ et al. [20], the prevalence of COPD in their clinic patients with cardiovascular diseases was $10.5 \%$, a figure much lower than ours. Only heart failure and ishaemic heart disease showed significant association with COPD when compared with non-COPD patients. However, it appears that patients recruited were those attending the cardiovascular clinics and did not require specific cardiovascular diseases as inclusion criteria for the study. Furthermore, the primary study objective was to evaluate the diagnostic reliability of combining a hand-held screening spirometry with a COPD questionnaire to screen these patients for COPD. These

\begin{tabular}{|l|l|l|l|l|l|}
\hline Variables & $\begin{array}{l}\text { Regression } \\
\text { co-efficient }\end{array}$ & $P$ & \multicolumn{2}{|l|}{$\begin{array}{l}\text { Adjusted } \\
\text { odd ratio }\end{array}$} & \multicolumn{2}{|l|}{ up\% Confidence Level } \\
\hline $\begin{array}{l}\text { Cigarette } \\
\text { smoking (ever) }\end{array}$ & 1.439 & 0.001 & 4.2 & 1.82 & 9.72 \\
\hline $\begin{array}{l}\text { Dyspnoea } \\
\text { (frequency) }\end{array}$ & 1.054 & 0.018 & 2.87 & 1.19 & 6.88 \\
\hline
\end{tabular}

Table 4: Logistic regression model predictive of COPD in subjects with cardiovascular diseases. two major methodology differences disallow meaningful comparison of our findings.

The association with pulmonary hypertension in COPD reported here is best explained as a recognized complication of COPD resulting from hypoxia-induced vascular remodeling [21], although it can occur independently [22]. The significant trend towards more severe COPD by GOLD classification in these patients favors a hypoxia cause (data not shown). The accuracy of this data may be compromised by the small number of our subjects having pulmonary hypertension and the availability of right heart echocardiography data in all subjects.

A key message of our study is that symptoms of breathlessness, cough and sputum, and significant cigarette exposure (including passive smoking), differentiates out COPD among patients with existing cardiovascular diseases. Such a history and exposure risk is no different from what is currently advocated to diagnose COPD [23]. Our findings add to its validity and reinforce the importance of spirometry for diagnosis. The poorer functional and quality of life status associated with these COPD patients are consistent with the moderate severity of COPD by GOLD criteria or maybe a higher cardiopulmonary burden imposed upon by both the respiratory and cardiac diseases. Interestingly, cough and sputum faded in significance in multivariate analysis, suggesting that the symptoms of chronic bronchitis may be a weak discriminator for COPD or phenotype less commonly observed in our local population. In fact, a recently published population-based survey on COPD in China, 70\% of 1668 patients with COPD did not have any history of chronic bronchitis [24]. We have also previously reported that chronic bronchitis as initial presenting complaint was lacking in a small group of severe COPD patients in Malaysia [10].

In contrast to a recent study by Partridge MR et al. [14] that showed that the COPD symptoms are worst in the mornings, the symptoms in our patients appear to be worse in the evenings although about $60 \%$ of them do not report of any particular tendency. This may be a manifestation of another COPD phenotype of Asians compared to that of Caucasians, although it is possible that the worsening of COPD symptoms in any particular time of the day is not necessarily a consistent feature in COPD.

In our study, we made an important assumption that airflow obstruction detected in these patients with cardiovascular diseases equates with COPD diagnosis. Such assumption is probably acceptable and does not lead to significant bias of our conclusions. In study by Wada $\mathrm{H}$ et al. [20], the use of a validated COPD questionnaire removed only 3 of the 82 subjects found to have airflow obstruction from being diagnosed COPD. An older age and the lack of bronchodilator reversibility lend more support to COPD than asthma. The use of fixed $\mathrm{FEV}_{1} / \mathrm{FVC}$ ratio, instead of LLN, as discriminator of airflow obstruction has been clearly shown to overestimate its prevalence in older patients [25]. Unfortunately, we cannot calculate LLN without having a reliable normative range of FEV and FVC as reference in Malaysia. Any LLN used here would also have to take into consideration the multi-ethnic influence of our patients. In our study, we have a reasonable spread of Malays, Chinese and Indians patients. The use of fixed ratio will allow a standardized comparison between prevalence studies of multi-ethnicity and of different countries, and reduces methodology complexities. Our findings also have the limitation of being confined to the observations from a single site only although we do not think that this would have caused a significant distortion of the findings.

It is unclear whether the co-existence of COPD and cardiovascular diseases is a simply a matter of concurrent existence of two common diseases or has important shared pathologic mechanisms like systemic 
Citation: Loh LC, Selvarajah N, Mohan S, Choo WS, Omar I (2011) Undiagnosed COPD in Patients with Established Cardiovascular Diseases: Prevalence, Symptoms Profiling and Functional Status. J Pulmonar Respirat Med 1:107. doi:10.4172/2161-105X.1000107

Page 5 of 5

inflammation with hastened acceleration in atherosclerosis [26]. These have become clinically important research questions today as active and effective intervention may be possible [27]. To have greater awareness of such co-existence and to reliably diagnose unsuspecting patients with cardiovascular diseases is relevant to our day-to-day clinical practice. Our data of its prevalence and predictive features add timely contribution to our current bulk of clinical knowledge.

\section{Acknowledgment}

The authors wish to acknowledge the kind assistance of the cardiology department staff in executing the study and the kind permission of Directo General, Ministry of Health Malaysia to publish the data. Also, the authors wish to thank the financial support of International Medical University Research \& Ethics Committee for this study.

\section{References}

1. Sin DD, Wu L, Man SF (2005) The relationship between reduced lung function and cardiovascular mortality: a population-based study and a systematic review of the literature. Chest 127: 1952-1959.

2. Calverley PM, Anderson JA, Celli B, Ferguson GT, Jenkins C, et al. (2010) Cardiovascular events in patients with COPD: TORCH study results. Thorax 65: 719-725

3. Agusti A, Calverley PM, Celli B, Coxson HO, Edwards LD, et al. (2010) Characterization of COPD heterogeneity in the ECLIPSE cohort. Respir Res 11: 122.

4. Rutten FH, Cramer MJ, Grobbee DE, Sachs AP, Kirkels JH, et al. (2005). Unrecognised heart failure in elderly patients with stable chronic obstructive pulmonary disease. Eur Heart J 26: 1887-1894.

5. Bursi F, Vassallo R, Weston SA, Killian JM, Roger VL (2010) Chronic obstructive pulmonary disease after myocardial infarction in the community. Am Heart J 160: 95-101.

6. Hawkins NM, Huang Z, Pieper KS, Solomon SD, Kober L, et al. (2009) Chronic obstructive pulmonary disease is an independent predictor of death but not atherosclerotic events in patients with myocardial infarction: analysis of the Valsartan in Acute Myocardial Infarction Trial (VALIANT). Valsartan in Acute Myocardial Infarction Trial Investigators. Eur J Heart Fail 11: 292-298.

7. Mascarenhas J, Lourenco P, Lopes R, Azevedo A, Bettencourt P (2008) Chronic obstructive pulmonary disease in heart failure. Prevalence, therapeutic and prognostic implications. Am Heart J 155: 521-525.

8. Hawkins NM, Petrie MC, Jhund PS, Chalmers GW, Dunn FG, et al. (2009) Heart failure and chronic obstructive pulmonary disease: diagnostic pitfalls and epidemiology. Eur J Heart Fail 11: 130-139.

9. Regional COPD Working Group (2003) COPD prevalence in 12 Asia-Pacific countries and regions: projections based on the COPD prevalence estimation model. Respirology 8: 192-198.

10. Loh LC, Lai CH, Liew OH, Siow YY (2005) Symptomatology and health status in patients with chronic obstructive pulmonary disease. Med J Malaysia 60: 570-577.

11. Bestall JC, Paul EA, Garrod R, Garnham R, Jones PW, et al. (1999) Usefulness of the Medical Research Council (MRC) dyspnoea scale as a measure of disability in patients with chronic obstructive pulmonary disease. Thorax 54 581-586.

12. Martin Dolgin (1994) Nomenclature and criteria for diagnosis of diseases of the heart and great vessels. (9thedn), Little Brown and Company, Boston, MA USA.

13. Jones PW, Quirk FH, Baveystock CM, Littlejohns P (1992) A self-complete measure for chronic airflow limitation. The St. George's Respiratory Questionnaire. Am Rev Respir Dis 145: 1321-1327.

14. Partridge MR, Karlsson N, Small IR (2009) Patient insight into the impact of chronic obstructive pulmonary disease in the morning: an internet survey. Curr Med Res Opin 25: 2043-2048.

15. Miller MR, Hankinson J, Brusasco V, Burgos F, Casaburi R, et al. (2005) Standardisation of spirometry. ATS/ERS Task Force Eur Respir J 26: 319-338.

16. Dirksen A, Madsen F, Pedersen OF, Vedel AM, Jenson AK (1996) Long term performance of a hand held Spirometer. Thorax 51: 973-976.

17. Quanjer PH, Tammeling GJ, Cotes JE, Pedersen OF, Peslin R, et al. (1993) Lung volumes and forced ventilatory flows. Report Working Party Standardization of Lung Function Tests, European Community for Steel and Coal. Official Statement of the European Respiratory Society. Eur Respir J Suppl 16: 5-40.

18. Hawkins NM, Jhund PS, Simpson CR, Petrie MC, Macdonald MR, et al. (2010) Primary care burden and treatment of patients with heart failure and chronic obstructive pulmonary disease in Scotland. Eur J Heart Fail 12: 17-24.

19. Light RW, George RB (1983) Serial pulmonary function in patients with acute heart failure. Arch Intern Med 143: 429-433.

20. Wada H, Nakano Y, Nagao T, Osawa M, Yamada H, et al. (2010) Detection and prevalence of chronic obstructive pulmonary disease in a cardiovascular clinic: evaluation using a hand held $\mathrm{FEV}_{1} / \mathrm{FEV}_{6}$ meter and questionnaire. Respirology 15: $1252-1258$.

21. Minai OA, Chaouat A, Adnot S (2010) Pulmonary hypertension in COPD: epidemiology, significance, and management: pulmonary vascular disease: the global perspective. Chest 137: 39S-51S

22. Sin DD, Man SF (2006) Is systemic inflammation responsible for pulmonary hypertension in COPD? Chest 130: 310-312.

23. Global Strategy for Diagnosis, Management, and Prevention of COPD. Updated 2009 Accessed: 1 December 2010.

24. Lu M, Yao W, Zhong N, Zhou Y, Wang C, et al. (2010) Chronic obstructive pulmonary disease in the absence of chronic bronchitis in China. Respirology 15: $1072-1078$.

25. Vollmer WM, Gíslason T, Burney P, Enright PL, Gulsvik A, et al. (2009) Comparison of spirometry criteria for the diagnosis of COPD: results from the BOLD study. Eur Respir J. 34: 588-597.

26. Sinden NJ, Stockley RA (2010). Systemic inflammation and comorbidity in COPD: a result of 'overspill' of inflammatory mediators from the lungs? Review of the evidence. Thorax 65: 930-936.

27. Maclay JD, McAllister DA, Macnee W (2007) Cardiovascular risk in chronic obstructive pulmonary disease. Respirology 12: 634-641. 